\title{
Research on Balanced Development Strategy of Compulsory Education in Ethnic Minority Areas Against the Background of Smart Education
}

\author{
Jiayang $\operatorname{Han}^{1}$ Yusha $\operatorname{Lin}^{1} \mathrm{Yu} \mathrm{Liu}^{1, *}$ \\ ${ }^{1}$ School of Public Affairs and Administration, University of Electronic Science and Technology of China, \\ Chengdu, Sichuan, China \\ *Corresponding author. Email: liuyu0414@uestc.edu.cn
}

\begin{abstract}
Due to historical and geographical factors, the development of ethnic minority areas in China is relatively backward, and the allocation of basic education resources can not keep up with the requirements of talent training under the new situation. Education has become an important factor limiting its economic development. Taking smart education as the background, this study analyzes how compulsory education is carried out and developed in ethnic minority areas, and sorts out the existing problems and causes in this process. Considering the opportunities brought by "Internet + Education" and the background that China has entered the stage of rural revitalization, this paper puts forward strategies to promote the balanced development of compulsory education in ethnic minority areas, and provides suggestions for the development of ethnic minority areas.
\end{abstract}

Keywords: Smart education, Minority areas, Compulsory education, Balanced education.

\section{INTRODUCTION}

Compulsory education is the key stage with the longest duration and the widest coverage in the complete education system, and it is also the cornerstone of national education. In the $21 \mathrm{st}$ century, with the rapid development of China's education, China has achieved the strategic goal of basically popularizing nine-year compulsory education according to the plan, and the topic of balanced development of compulsory education has also attracted increasing attention.

In recent years, with the increasing development speed of education, education has begun to enter the "information age". Smart education is the advanced stage of development in this era. It is an educational behavior with high learning experience, high content adaptability and high teaching efficiency provided by schools, regions or countries.[1] It is an educational behavior method

*Fund: This paper is supported by the Humanities and Social Science Research Youth Fund Project of Ministry of Education - Research on the Supply and Improvement of Educational Public Service in Ethnic Minority Areas in Western China (18YJCZH111). based on advanced intelligent informatization equipment, and supported by high-quality intelligent educational resources and auxiliary learning tools. [2]

In 2020, China's anti-poverty war has won a comprehensive victory. Consolidating and expanding the achievements of anti-poverty war, comprehensively promoting rural revitalization and accelerating agricultural and rural modernization have become the focus of social attention and development. General secretary Xi Jinping has stressed many times that "we can achieve a well-off society in an all-round way, and none of the minority nationalities should be left behind." [3] Restricted by natural conditions, development foundation, social development degree and other factors, the poverty in ethnic minority areas is "large in quantity, wide in scope and deep in degree", and the economic and social development is relatively backward. The ethnic minority area should be the key area to build a well-off society in an all-round way, and also the "short board" to promote the rural revitalization strategy.

Reviewing the current situation of poverty alleviation in some minority areas, education has 
become an important factor limiting their economic development. The development of compulsory education can not keep up with the requirements of the development of modern education under the new situation. The lack of talent training stamina restricts the development of regional economy, which easily leads to a vicious circle of poverty. The rapid progress of Internet technology provides more opportunities for the improvement of the quality of compulsory education and teaching conditions in minority areas.

To sum up, based on the background of smart education, this paper discusses and proves what opportunities the Internet can bring to realize the balanced development of compulsory education in minority areas, and discusses how to promote the balanced development of compulsory education in minority areas.

\section{ANALYSIS OF THE CURRENT SITUATION AND PROBLEMS OF COMPULSORY EDUCATION IN ETHNIC MINORITY AREAS IN CHINA}

\subsection{Measures and Results of Balanced Development of Compulsory Education in Ethnic Minority Areas in China}

\subsubsection{Increasing Funding and Improving Conditions of Running School}

With the increase of national financial support, the public financial investment in education in ethnic minority areas is increasing, the infrastructure construction is improving, and the average level of public funds for public education students is increasing. The teaching environment in ethnic minority areas has been greatly improved, and the school-running level and education guarantee ability have been effectively improved. For example, the investment in public education per student in Ganzi Prefecture has increased from 30.215 million yuan in 2016 to 126.022 million yuan in 2019, and the total investment in infrastructure has also increased from 46.18268 million yuan in 2016 to 102.2077 million yuan, both of which have doubled, greatly improving the school-running conditions of Ganzi Prefecture. With the increase in educational investment, the construction of primary and secondary schools in ethnic minority areas has been improved, and teaching facilities and equipment such as students' living equipment, experimental instruments and books have been upgraded and improved. Many schools have also added informationized teaching equipment to promote the development of smart education.

\subsubsection{Increasing Investment in Teachers and Building a Team of Teachers}

In ethnic minority areas, measures such as actively introducing teachers, rotating teachers for exchange, strengthening teacher training and improving teachers' remuneration have effectively expanded the number of teachers, improved the quality of teachers and adjusted the structure of teachers.

First, it is required to actively recruit new teachers. By introducing free normal university students and recruiting teachers in special posts, it is necessary to expand the number of full-time teachers and improve the weak teachers in schools in ethnic minority areas. Second, it is to strengthen teachers' in-service training. Tailor-made and highly professional in-service training for teachers will be carried out in local minority areas. On this basis, teachers should be organized to accept more advanced education teaching and training, or learn from the excellent teachers by means of online learning, so as to promote the comprehensive level of teachers in ethnic minority areas. Third is to implement teacher rotation system. The reasonable flow of teachers contributes to the balanced allocation of educational teachers, especially in ethnic minority areas. [4] Excellent teachers flow between schools, which brings advanced knowledge and teaching methods to teachers and students in weak schools, and promotes the balance of teachers. Third is to improve the treatment of teachers. In order to mobilize teachers' work enthusiasm, it must grant allowances and subsidies and implement performance-based pay.

\subsubsection{Taking Effective Measures to Implement the Strategy of "Controlling the Dropping Out"}

In recent years, in order to fully implement the requirement of "striving to ensure that every child can enjoy fair and quality education", ethnic minority areas have adopted a variety of measures to carry out basic education, whcih improves the situation of students dropping out of school and ensures that children of all ethnic groups are willing, happy and able to learn in school. For 
example, it is required to check the student's school status, collect the school-age children (teenagers) who did not enter school in time, and give compulsory education subsidies. At the same time, in order to avoid the intergenerational transmission of poverty caused by students dropping out of school, Ganzi Prefecture has taken the work of "protecting students from dropping out of schools" as the focus in recent years, further strengthened the publicity of "protecting students from dropping out of schools", and made every effort to ensure that school-age children (teenagers) enjoy the equal right to receive compulsory education. Through the "free lunch", "student subsidies in high altitude areas" and other policies, it ensures that students do not drop out of schools due to family financial difficulties. On the whole, the number of students in primary and junior high schools and the retention rate of basic education in ethnic minority areas are on the rise, and the policies of "protecting students from dropping out of schools" and "ensuring school enrollment" have achieved good results.

\subsubsection{Developing Smart Education and Promoting Educational Informatization}

In order to share high-quality educational resources with developed areas and narrow the educational gap between ethnic minority areas and developed areas, in recent years, ethnic minority areas have actively developed smart education and made full use of modern information technology to solve the problems of educational shortcomings in ethnic minority areas. For example, after several years of exploration and practice, Ganzi Prefecture has constructed the overall framework of "123" mode of smart education, and carried out two kinds of complementary distance and network teaching, which effectively solved the problem of lacking high-quality teaching resources in Ganzi Prefecture. With the development of smart education and the improvement of education informatization, it can improve the ability of sharing high-quality educational resources, enrich the educational resources of the educated children in ethnic minority areas, and effectively improve the quality of education in ethnic minority areas.

\subsection{Problems Existing in the Unbalanced Development of Compulsory Education in Ethnic Minority Areas in China}

\subsubsection{Weak Faculty}

At present, there are still many problems in the quantity, quality and structure of teachers in ethnic minority areas, and the weakness of teachers restricts the development of compulsory education in ethnic minority areas.

First, there is a gap in the number of full-time teachers. From the perspective of the total number of teachers in basic education in ethnic minority areas at present, the small number of full-time teachers means that each teacher will undertake teaching tasks far beyond the national standard, which will not only affect the development of teachers themselves, but also cause a certain negative impact on the quality of teaching.

Second, the rationality of the composition structure of teachers can still be improved. The subject structure and age structure of liberal arts teachers being more than science teachers and middle-aged and old teachers being more than young teachers are common, and it is difficult to adapt to the modern smart teaching model. The shortage of bilingual teachers makes it difficult to carry out bilingual education and improve the teaching quality.

\subsubsection{Difficult School-running Conditions}

Due to limited funding and bad natural environment, it is difficult for minority areas to have good conditions for running schools. In a large number of primary and secondary schools in ethnic minority areas, the construction of teaching buildings, sports fields and other infrastructure facilities have not reached the standard, let alone modern teaching facilities such as multimedia classrooms and computer rooms. The infrastructure of some schools can only meet the requirements of daily teaching, and the quality and function are not guaranteed. Some of the teaching equipment in some schools is out of repair and can not be used. In addition, the harsh geographical environment and inconvenient transportation also make the cost of running schools in ethnic minority areas high and the conditions of running schools very difficult. 


\subsubsection{Imbalanced Investment in Teaching Funds}

In recent years, with the support of the national finance, the investment in education funds and the increase in subsidies in ethnic minority areas, there are still some problems such as the unfair allocation of teaching funds and regional imbalance. Influenced by economic development, there are differences in public financial investment in education in various ethnic minority areas, even in different areas within the same ethnic minority area. For example, the public expenditure per student of Ganzi Prefecture has been increasing year by year, and the public expenditure per student in most areas have been higher than the national standard, while Danba County, Xiangcheng County, Daocheng County, Derong County, Hailuogou County and other counties and cities have not met the national standard and requirements.

\subsubsection{Teaching Quality Cannot Be Guaranteed}

In minority areas, many schools lack modern educational resources and cannot make rational and efficient use of existing educational resources, which makes it difficult for the quality of education in minority areas to be fully guaranteed.

First of all, the lack and inadequate use of teaching facilities and equipment can hardly promote the improvement of teaching quality. More schools in remote ethnic minority areas lack various experimental equipment for biology, chemistry and physics, as well as teaching tools for subjects such as sports, music and fine arts, which cannot meet the teaching needs. [5] Under such circumstances, teaching utensils that should promote teaching and improve teaching quality do not play a full role, and teaching quality is difficult to be guaranteed. Secondly, ethnic minority areas often lack excellent professional teachers, and excellent bilingual teachers are even fewer, so it is difficult to meet the needs of bilingual teaching or guarantee highquality teaching. In addition, ethnic minority students in remote areas cannot get the same educational resources as students in developed areas, and lag far behind in teaching content, teaching methods, teaching concepts, and so on. Therefore, there is a big gap in teaching quality.

\subsection{Reasons for the Unbalanced Development of Compulsory Education in Ethnic Minority Areas in China}

\subsubsection{Teachers}

First of all, ethnic minority areas are often geographically remote, with harsh natural environment and living conditions, making it difficult to introduce and retain teachers and to guarantee the number of teachers. Secondly, there are few opportunities for teacher training in minority areas, and the form of training is single. The professional level and teaching level of teachers still need to be improved. Teachers can not actively adapt to the information education, so it is difficult for schools to carry out the smart education in the Internet era. [6] In addition, the management system of teachers in ethnic minority areas is not perfect enough, the staffing of basic education staff is relatively in shortage, and some areas are difficult to make up for the shortage of local finance. Finally, the salary management mechanism of teachers in ethnic minority areas is still not perfect, and there is still much room for improvement in material and spiritual incentives, as well as teachers' benefits.

\subsubsection{System}

The system root of the unbalanced development of compulsory education in ethnic minority areas is the common prosperity principle of "getting rich first leading to getting rich later". The minority areas are mostly distributed in the western mountainous areas, where the human and geographical conditions for economic development are poor and the level of economic development is low. Although in recent years, the state pays more and more attention to the education development of ethnic minority areas, and continues to strengthen the investment of education in ethnic areas. However, from the point of development results, the benefit of policy arrangement and financial input in developed areas is always higher than that in minority areas, and the minority areas are still short of funds and resources and have not yet made qualitative improvement.

\subsubsection{Policy}

First of all, the structure of financial input is unbalanced, which is mainly manifested as the imbalance between central and local financial input, and the difference of local government financial 
input is caused by the different levels of economic development in ethnic minority areas. Secondly, some education policies are not targeted. State education departments often take students from developed areas as the standard when drawing up education policies, without taking into account the huge differences in educational environment, educational resources and acceptance degree between students from ethnic minority areas and those from other developed areas, resulting in difficulties for students from ethnic minority areas to adapt and accept.

\section{COUNTERMEASURES TO BOOST THE BALANCED DEVELOPMENT OF COMPULSORY EDUCATION IN ETHNIC MINORITY AREAS WITH SMART EDUCATION}

\subsection{Increasing the Education Funds and Ensuring the Conditions for Informationized Schooling}

Adequate educational funds are the important material support for schools to run and employ teachers. In the era of "Internet $+"$, to carry out smart education in ethnic minority areas also needs certain hardware and software conditions, and the primary condition is stable educational funds and educational resources input.

First, it is required to build and improve smart education facilities and increase the level of financial aid to poor students. For the construction, operation and long-term maintenance of smart education facilities, it needs to establish corresponding fund standards. On the one hand, educational resources and funds should be allocated reasonably, giving priority to and guaranteeing the informationization construction of educational infrastructure. On the other hand, it is suggested that schools set up special management and maintenance of various information equipment in school.

In addition, it is necessary to implement the subsidy policy for students from poor families and establish a comprehensive subsidy policy system, including the reduction and deduction of tuition fees, miscellaneous fees, book fees, homework fees, free pre-school education plan, free lunch subsidy plan, and student nutrition improvement plan, and winter heating subsidies for students in high altitude areas.
Second, it is required to enhance the integration degree of educational information resources and accelerate the sharing of resources in time. It is the top priority to improve the quality of compulsory education in ethnic minority areas to open a large number of high-quality educational information resources to ethnic minority areas and share them in real time so that they can quickly enter the classroom teaching field and play a role. Therefore, it is necessary to increase the investment of capital and manpower, organize an expert team, and develop the software suitable for multimedia teaching which is matched with classroom teaching for teachers in ethnic minority areas to use specially, so that teachers and students in ethnic minority areas can share high-quality information resources.

\subsection{Strengthening the Construction of Teachers and the Concept of Smart Education}

In order to improve the stability of teachers in ethnic minority areas and the professional level of local teachers, first of all, it is necessary to establish an effective talent introduction mechanism and teacher guarantee mechanism. In the aspect of talent introduction, it is required to further strengthen publicity and welfare attraction, encourage outstanding talents to take root, further improve the teacher salary performance system, and increase the subsidies to teachers in ethnic minority areas, especially in rural areas. At the same time, the incentive mechanism can be further improved, with the focus on access, improvement of ability and quality, and treatment, etc., to increase the reward for high-quality teachers. For example, preferential policies can be given to high-quality teachers in the process of professional title evaluation, so as to retain excellent teachers and avoid the continuous loss of teachers.

With the help of smart education platform and based on "Internet + ", the construction of public service platform for education resources in ethnic minority areas can not only provide better course content for students in ethnic minority areas, but also help improve teachers' teaching level.

Through the use of a series of information means, the constraints of time and space can be broken, and smart education business can be developed, such as network collaborative office, remote network teaching and research, remote collaborative management, remote synchronous course competition, network information exchange 
and consultation, remote video training, etc. The application of these new means plays an important role in promoting the deep integration of education and teaching, teaching and research discussion, teacher construction, campus governance and information technology and improving the teaching efficiency.

Combining advanced educational and teaching means with high-quality educational resources can promote the steady improvement of education and teaching quality in ethnic minority areas against the background of rural revitalization.

\subsection{Accelerating the Pace of Smart Education and Breaking the Regional Barriers of Education}

In order to share high-quality educational resources with developed areas and narrow the educational gap among ethnic minority areas, developed areas, prefectural regions and urban and rural areas, modern information technology should be fully used to solve the shortcomings of compulsory education in ethnic minority areas. First of all, it is necessary to strengthen the use of modern information technology equipment, continue to vigorously develop distance education, and on this basis, introduce information technology talents, and strengthen the training of education workers' information technology ability. At the same time, it is required to establish special education information equipment and network operating funds, in order to ensure that education information equipment can be effectively used and maintained and the idle waste of resources can be avoided. In addition, it is necessary to guarantee the daily update and maintenance of school equipment, logistical support and other funds to provide a better learning environment for students.

With the increasing integration of "Internet +" and compulsory education, the channels for the convergence and transmission of various educational and teaching resources are also expanding. The popularization of smart education can make high-quality educational resources break through the limitations of objective factors such as time and space, promote the efficient flow of educational resources between ethnic minority areas and developed areas, urban and rural areas, break down the educational regional barriers, and realize the balanced development of compulsory education.

\section{CONCLUSION}

The century-old plan is based on education. How to realize the balanced development of compulsory education in ethnic minority areas is not only an educational problem, but also a diversified and comprehensive problem, which is closely related to politics, economy, society and other aspects. The solution of this problem plays a decisive role in accelerating economic development, enhancing regional coordination, optimizing social harmonious atmosphere and building a strong country in education. Since the reform and opening up, the Chinese government has accelerated the pace of promoting the balanced development of compulsory education and made remarkable achievements. However, due to the limitations of some objective conditions in China, the inherent deficiencies of ethnic minority areas such as geographical location and resource reserves, as well as the people's growing demand for high-quality education, the problem of inadequate and unbalanced development in China's ethnic minority areas is still very serious. Entering the new era, China's education work should focus on developing fairer and higher quality education. One of the important measures is to promote the high-quality and balanced development of compulsory education in ethnic minority areas.

"Internet + " plan is put forward to solve this problem. Against the background of smart education, it is required to take the Internet as the technical means, take the government as the leading role, unite with education departments, schools, internet education enterprises and teachers, integrate high-quality education resources, strengthen cooperation and exchanges between teachers in minority areas and developed areas, and strengthen supervision. It is believed that with the joint efforts of all parties, the problems of low quality of compulsory education and weak teachers in schools in minority areas will be solved one by one, so as to promote the balanced development of compulsory education in ethnic minority areas, speed up the implementation of educational equity, and provide education to people.

\section{AUTHORS' CONTRIBUTIONS}

Jiayang Han is responsible for searching for information and writing the draft of the paper; Yusha Lin is responsible for article modification and sentence perfection; Yu Liu is responsible for framing and directing the writing. 


\section{REFERENCES}

[1] Huang Ronghuai. The Triple Realm of Smart Education: From Environment, Model to System [J]. Modern Distance Education Research, 2014(06): 3-11. (in Chinese)

[2] Qiu Xuelian, Qi Zhenguo.Cultivation of Students' Core Literacy Based on the Background of Wisdom Education [A]. Teaching Steering Committee of Higher Education Technology Major, Ministry of Education. Research on the development of education innovation toward the era of wisdom - Proceedings of the 16th International Forum on Educational Technology and the First International Symposium on Intelligent Education [C].Teaching Steering Committee of Education Technology Major of Ministry of Education: Jiangsu Engineering Technology Research Center of Education Informatization, 2017:4. (in Chinese)

[3] State Ethnic Affairs Commission. The Central Conference on Ethnic Work Guide for Spiritual Learning $[\mathrm{M}]$. Beijing: Ethnic Publishing House, 2015. (in Chinese)

[4] Zhou Jun, Ge Xinbin. Strategic Considerations on Promoting the Quality and Balanced Development of Compulsory Education at Counties in Ethnic Regions - A Case Study of Xizang Region [J].Zhengzhou Normal Education, 211,10(01):11-14. (in Chinese)

[5] Yuan Mei, Yan Ziqian. A Study on Balanced Development of Compulsory Education in Minority Areas of China [J]. Journal of Nanning Normal University (Philosophy and Social Sciences Edition), 2020, 41(06):93102. (in Chinese)

[6] Wu Hongchao. Research on the Development of Compulsory Education in Ethnic Areas under the Background of Basis Equalization - Based on the Investigation and Analysis of 26 Ethnic Counties in 9 Provinces (Regions) in East, Central and West [J]. Journal of Central China Normal University (Humanities and Social Sciences Edition), 2020, 59(05): 166-174. (in Chinese) 